\title{
Evaluation of a PV Powered EV Charging Station and Its Buffer Battery
}

\author{
Hengbing Zhao and Andrew Burke \\ Institute of Transportation Studies, University of California, Davis, CA 95616, USA
}

Received: December 14, 2015 / Accepted: January 05, 2016 / Published: February 29, 2016.

\begin{abstract}
This research analyses the operation of a solar PV powered electric vehicle charging station with energy storage, that has been developed and demonstrated at the University of California-Davis, West Village, the largest planned zero-energy consumption community in the U.S. The intelligent energy management approach introduces solar PV electrical energy forecasting and EV (electric vehicle) charging demand projection to optimize the SOC (state of charge) of the buffer battery. The charging station has been operated continuously and routinely used by several EV users for a year. The actual operation shows that, a workplace charging station equipped with a buffer battery and with intelligent energy management can lower and reduce the station's peak power demand, and reduce the energy exchange with the utility grid by a factor of 2 . The battery recharging power demand was shifted away from the on-peak time periods to the off-peak time periods, which will benefit the charging station owner from less energy use during peak periods when time-of-use rates are higher. The standard cell voltage deviation of the 220 cells was calculated to analyse the battery cell consistency during the resting, charging and discharging periods. The analysis shows that, the $22050 \mathrm{Ah}$ cells show excellent voltage consistency with voltage deviation of less than 0.005 V within the battery SOC of $20 \%-80 \%$. The voltage deviation doubles when the battery SOC reaches $90 \%$. The comparison of cell voltage deviation at the beginning and after one year operation indicates that, the battery shows perfect cell voltage consistency and there is no obvious consistency deterioration during the battery resting, charging and discharging periods.
\end{abstract}

Key words: EV, charging, solar energy, power management, intelligent.

\section{Introduction}

PEV (plug-in electric vehicles) are expected to become much more common in upcoming decades. California's ZEV (zero-emission vehicle) Action Plan calls for 1.5 million ZEVs on the road by 2025. Most of ZEVs will be PEVs including electric-only PEVs and PHEV (plug-in hybrid electric vehicles). Presumably EV (electric vehicle) charging will occur at night during off-peak demand hours, when electricity price are relatively low. However, at least some EV charging will be needed during the day and even peak demand time periods. This will require the same sort of ubiquitous electric vehicle charging infrastructure, also known as EVSE (electric vehicle supply equipment). On the utility side, the electricity sector is increasing

Corresponding author: Hengbing Zhao, project scientist, research fields: advanced vehicles, fueling/charging stations, energy storage. the share of total electricity generated from renewable sources such as wind and solar. The efficient use of renewable energy resources relies on the ability to store energy, when it is produced and disburse it when it is needed. Both EV charging and renewable power sources pose challenges to decades-old electrical grid systems. Growing demand for EV charging facilities may play a role in meeting the challenges of $\mathrm{EV}$ charging and the renewable electricity grid. Therefore, building and installing EVSEs requires long-term and smart infrastructure investment. Properly designed EV charging stations not only benefit EV owners, but also the businesses that provide charging services and the utility grid.

Various EV charging stations have been developed recently [1-8]. Most of EVSEs are connected to the grid directly, which incurs the high cost of demand charges caused by spikes in power usage, often a barrier to 
installing EV changing stations. Demand charges are part of every commercial electricity bill and are determined by the highest $15 \mathrm{~min}$ of use during a billing cycle. In California, rates can skyrocket during midday periods of high demand in summer. Some solar PV-EVSE (PV-powered EV charging stations) can reduce high power demand during peak times, but are subject to the change of the weather. Battery-integrated EVSEs can significantly smooth the charging spikes and mitigate charging from on-peak time to off-peak time. Combining EVSE with an ESS (energy storage system) and solar PV eliminates the high cost of demand charges caused by spikes in power usage and maximizes the usage of renewables locally. Using storage batteries and solar PV panels with intelligent energy management system reduces the energy exchange with the grid, manages and smooths EV charging demand spikes, and avoids high demand charges during on-peak time periods. A solar PV-ESS-EVSE (PV powered EV charging station with energy storage) may be more efficient and economical than a solar PV-EVSE (PV-integrated EV charging stations) and a charging station with buffer battery only.

A Solar PV-integrated electric vehicle charging station with energy storage (Fig. 1) has been developed and demonstrated at the University of California-Davis, West Village, the largest planned zero-energy consumption community in the U.S. The charging system has a $5 \mathrm{~kW} \mathrm{PV}$ array, a $6.6 \mathrm{~kW}$ level 2 charging unit, a $35 \mathrm{kWh}$ lithium iron phosphate battery pack, and a $10 \mathrm{~kW}$ load response bi-directional inverter. The bi-directional inverter controls power flow between the different units. It has two DC ports which are connected to the PV panel and battery storage and two AC ports tied to the utility grid and EV charger, respectively. The solar PV electrical energy forecasting and EV charging demand projection are introduced to the energy management system to optimize the SOC (state of charge) of the buffer battery, maximize the usage of PV electricity for EV charging, and avoid EV charging during peak hour time.

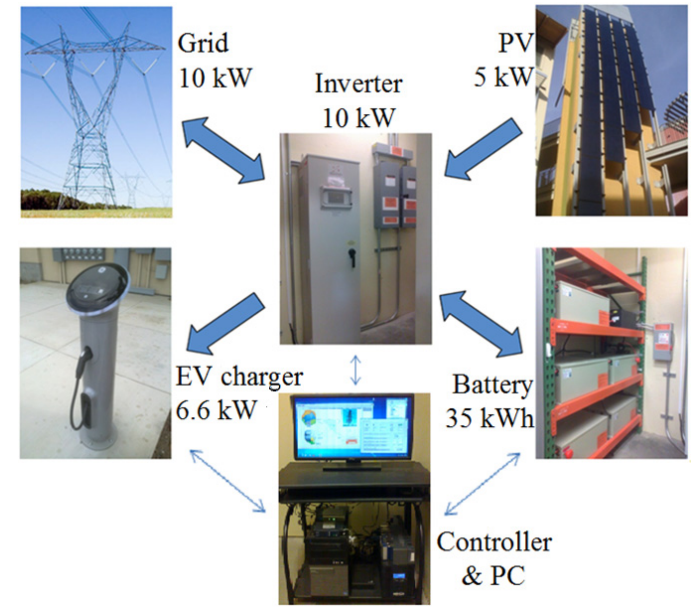

Fig. 1 Charging station system.

The charging station has been operated continuously and used by several EV users for a year. The EV charging load, PV power, grid power, and the cell voltage of each 220 cells have been recorded every minute. The research collects data from both the BMS (battery management systems) and the real-time controller and assesses the system operation and evaluates the battery performance. This paper is organized as follows. First, the power flow control, solar PV electricity forecasting, EV charging projection, and the battery optimization are descripted. Then, the data from each unit are analysed for assessing the control strategy, and the cell voltage standard deviations are calculated for evaluating the cell consistency. Finally, the conclusions and future work are presented.

\section{System and Control}

\subsection{Power Flow Control}

The control strategy has been developed to maximize PV energy for EV charging, and reduce energy exchange with the grid and peak power demand from the grid. When an EV is plugged into the charger, $\mathrm{PV}$ power is used to charge the $\mathrm{EV}$ if it is available. If more power is needed, the remaining power is provided by the battery or/and the utility grid. If no electric vehicle is plugged-in, PV energy is stored in the battery and if the battery is completely charged, excess PV 


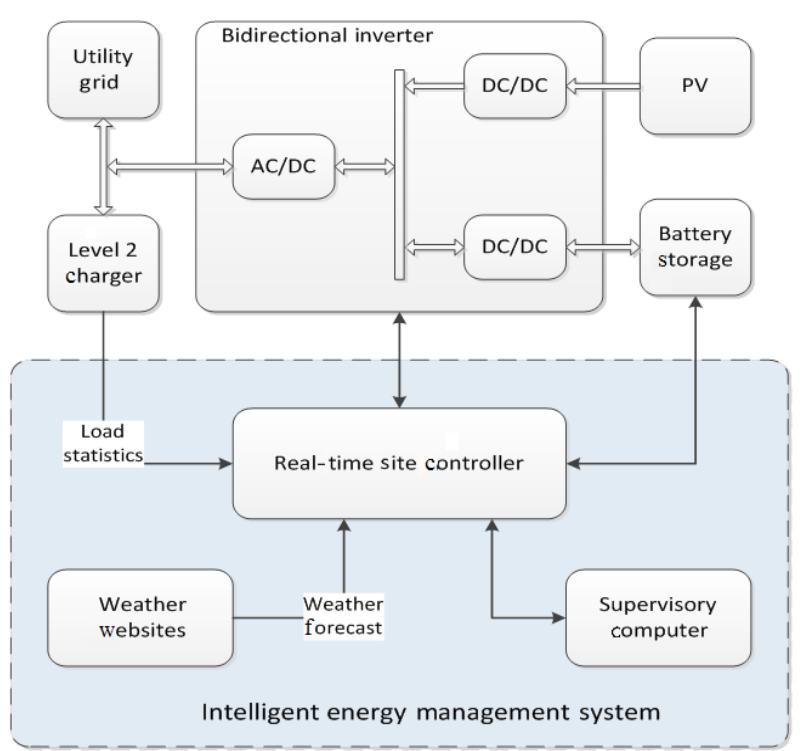

Fig. 2 Charging system block diagram.

power is fed into the utility grid. During off-peak hours, grid power is used to bring the battery state-of-charge up to an optimal level if the battery charge is low. The optimal battery SOC is calculated based on the PV electricity estimation and the EV charging demand projections. Energy is never fed to the grid from the battery in the present system. Fig. 2 shows the system block diagram.

\subsection{EV Charging Demand Projection}

Various short-term, medium and long-term load forecasting approaches for the electric utility industry have been developed for planning and operating utility grids. Most methods use statistical techniques based on historical data including load, weather, date and time factors. However, EV charging as a highly variable load is dependent on driving pattern, charging habit and time factors including the day of the week and holidays. It is not possible to accurately predict the EV charging events/power at a particular time, but for a community-used workplace charging station, the number of EVs and the charging habit are relatively stable and average usage can be predicted. Hence the probability of EV charging and aggregated electricity demand on a certain day can be forecasted utilizing recent historical charger use data.
In order to simplify the EV charging load forecasts and to avoid the use of the unavailable information, a statistical model that determines the load model parameters from the historical use data of the latest six week period has been developed. Aggregated EV charging demand on a certain day is projected by using similar-day-of-week approach, which is based on collecting and searching historical EV charging data for the same day of the week as the forecast day. The linear fit of historical EV charging usage data using the least squares method is employed to project the charger demand for each day of the week.

\subsection{Solar Electricity Forecasting}

The solar power output depends on the incoming solar insolation and the solar panel characteristics. The solar insolation on the assigned solar panel for a clear sky was calculated as a function of the day of year and the time of day, multiplied by the cosine of the angle between the normal to the panel and the direction of the sun from it. The actual solar insolation on the solar panel varies with the change of the state of the sky. Different layers of the atmosphere absorb or reflect different wavelengths of solar insolation. In this study, the most common indicator of the state of the sky, percent cloud cover, is taken into account in calculating the solar electricity. To simplify the forecasting, the percentage of cloud cover is regarded as the percentage attenuation of solar insulation compared to that for a clear sky on the solar panel. The cloud cover is extracted from OpenWeatherMap website.

\subsection{SOC Optimization}

Since most EV charging for a workplace charging station occurs in the relatively early morning and PV energy production is weak during this period, the available energy from the battery should be sufficient to meet the projected EV charging demand to avoid EV charging from the grid during peak hours. Hence the battery SOC to start the day should be maintained at a level dependent on the difference between the 
estimated PV energy generation and the projected EV charging demand for that day. If the current SOC is less than the projected SOC needed to meet the charge station demand, the battery should be charged from the grid during the off-peak hours.

\section{Data Analysis and Results}

The charging station has been operated continuously and used by several EV users for a year. The system had been shut down several times due to problems with the inverter, the charging station, and logging during this period, but most of the data are complete. The EV charging load, PV power, grid power, and the cell voltage of each 220 cells are obtained from the inverter and the battery management system. These data are logged into the supervisory computer every minute.

\subsection{System Operation Evaluation}

Using a PV-integrated EV charging station with energy storage has some notable synergies with benefits to both the charger users and operators. The energy storage can buffer and localize solar PV electricity for EV charging and reduce $\mathrm{EV}$ charging power demand from the grid during peak-demand periods. To understand the benefit of a battery buffered EV charging station, the actual PV power and the EV charging load over a year are shown in Fig. 3. The grid power and the battery power are given in Figs. 4 and 5, respectively. The results show that the charging system with the intelligent energy management can localize PV electricity for EV charging and almost eliminate EV charging power demand from the grid and shift battery replenishing into off-peak periods if needed.

The PV electricity, EV charging load, the grid electricity consumption, and the electricity fed back to the grid are integrated to evaluate the energy exchange between the system and the utility grid. Fig. 6 shows the generated PV electricity, EV load, and the energy required from and fed back to the grid in a month. To compare with the PV-integrated charging system without energy storage (PV-EVSE), the difference of

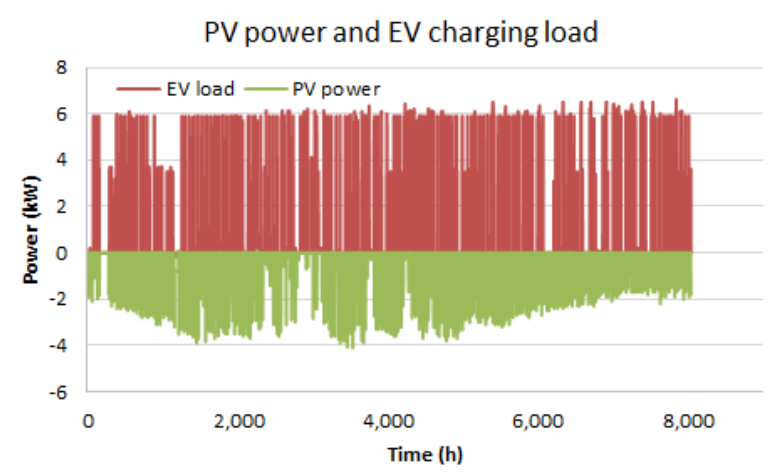

Fig. 3 PV power and EV charging load.

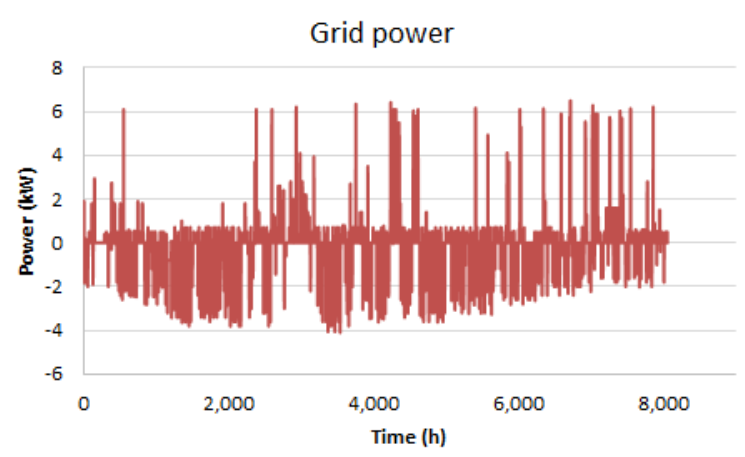

Fig. 4 Grid power.

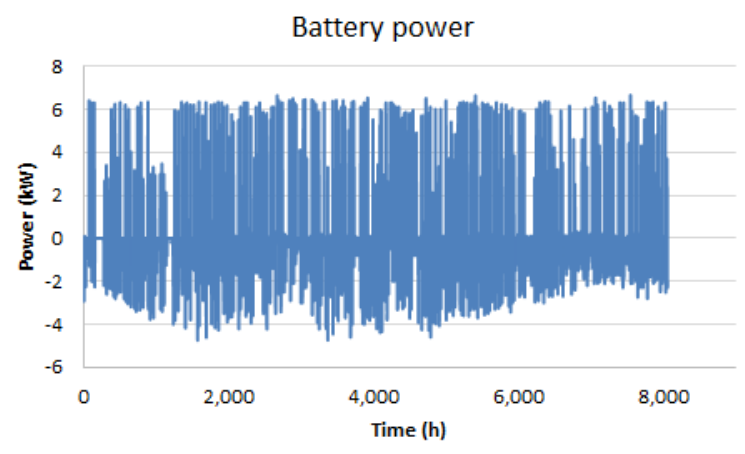

Fig. 5 Battery power.

$\mathrm{PV}$ power and the EV charging power are also accumulated and plotted in Fig. 6. The PV-integrated charging station with energy storage (PV-ESS-EVSE) can reduce the energy requirement from the grid by 60 percent. Most of grid electricity consumption happens during off-peak demand periods to replenish the battery if needed. Most of PV electricity is used for EV charging or stored in the energy storage. Less than 40 percent of PV electricity is fed back to the grid, which can significantly reduce the losses on transmission lines. 
Cumulative energy in Feb. 2015

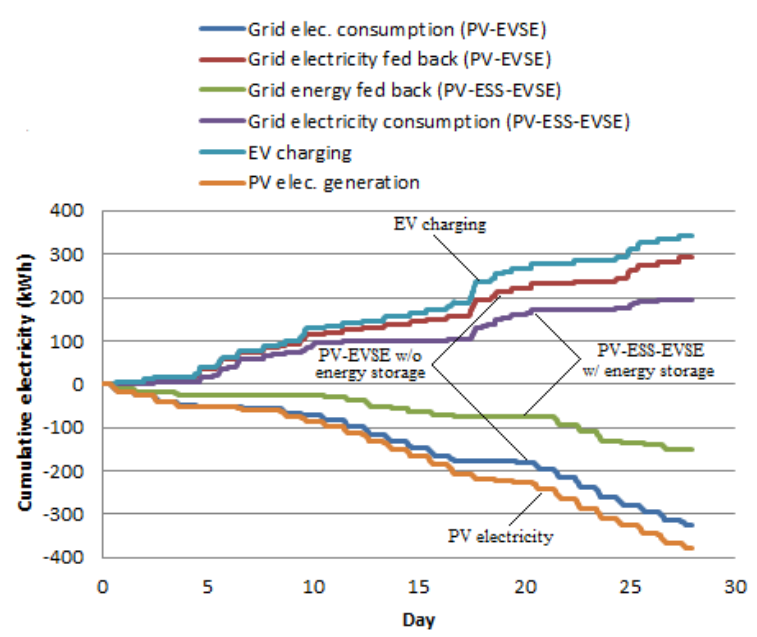

Fig. 6 Cumulative energy over a month.

\subsection{Load Projection and PV Forecast}

EV charging load forecasting is vitally important for the economic operation and optimum control of the solar powered battery buffered EV charging station. The historical EV charging data of the latest six week period is collected and searched to project the EV charging demand of the same day of the week as the forecast day by using the linear fitting. The projected daily charging load and the measured daily charging for a period of about 10 months are given in Fig. 7 . Since the charging station is a workplace charging station, the charging pattern changes with the day of week. The daily charging data on specific days of the week-Monday, Wednesday, Friday and Sunday are plotted on a weekly basis in Fig. 8. The projected EV charging load approximately reflects the actual

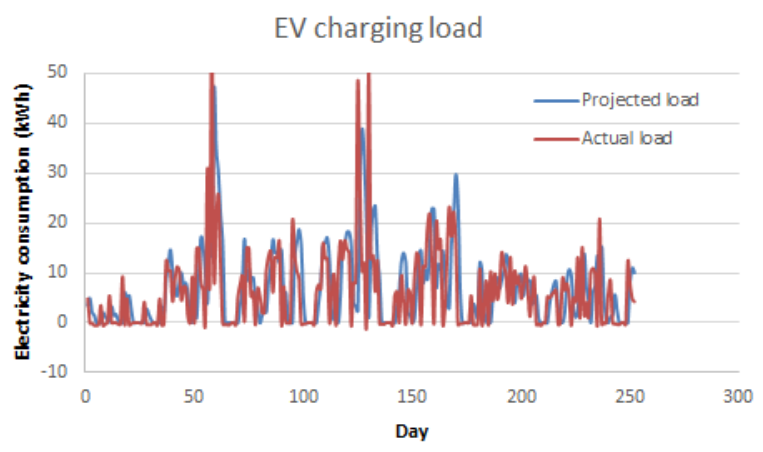

Fig. 7 EV charging load.

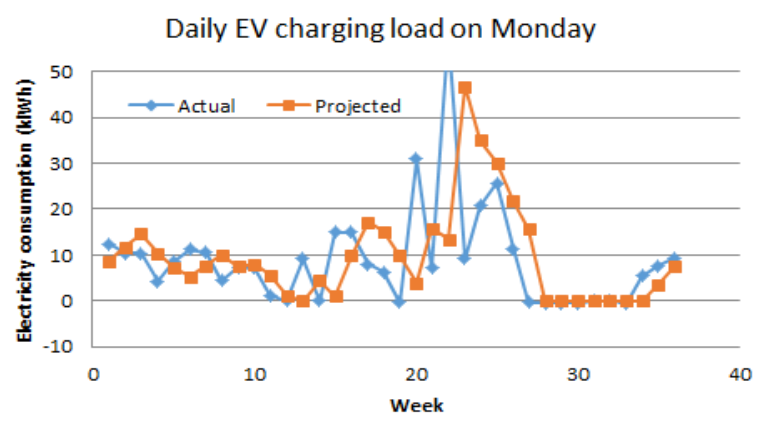

(a)

Daily EV charging on Wednesday

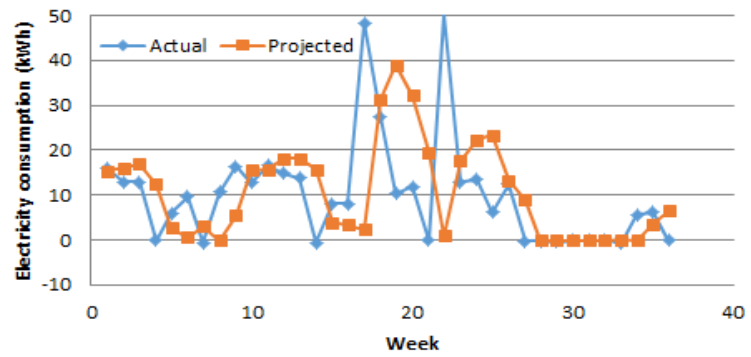

(b)

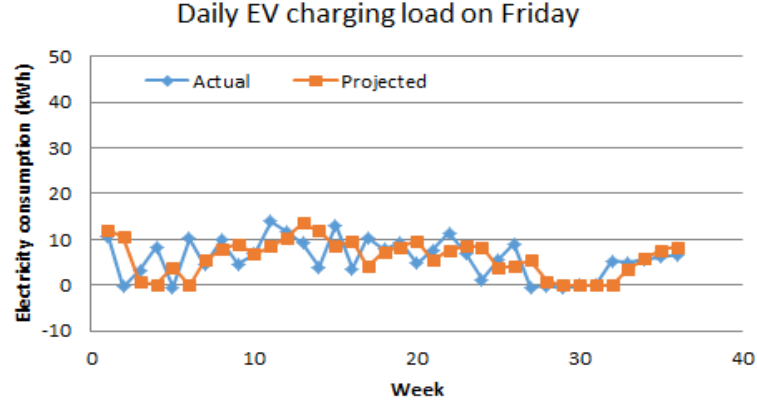

(c)

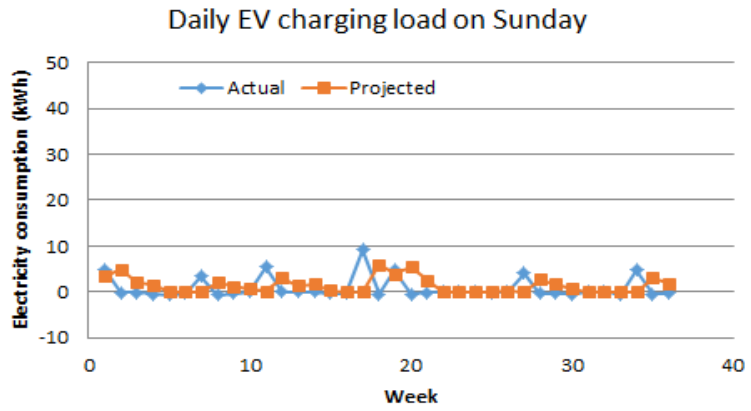

(d)

Fig. 8 EV charging load on the similar day of the week.

charging load variation and the charging pattern during a week. Since the current charging station has only one outlet, the uncertainty and contingency will affect the result of the load demand projection. 
The estimated PV electricity and the actual PV electricity generation are shown in Fig. 9. Since the 3-hour weather forecast is used to evaluate the PV generation, the cloud cover information is not accurate. Other factors may also affect the PV output. There is 10-20 percent difference between the estimated PV electricity and the actual PV electricity, which happens on both clear and cloudy days. However, the projected PV electricity reflects the trend of the actual PV generation, and is still useful for energy management of a charging station.

The battery target SOC is optimized based on the estimated PV electricity and the projected EV charging load. Unlike other battery buffered charging stations, in which the battery is fully replenished during off-peak hours, the battery in the present system is recharged only if the battery SOC is less than the optimal target SOC at night. This approach will optimize the usage of energy storage and minimize energy exchange with the grid. Fig. 10 shows the optimized target SOC on a daily basis over a 10-month period.

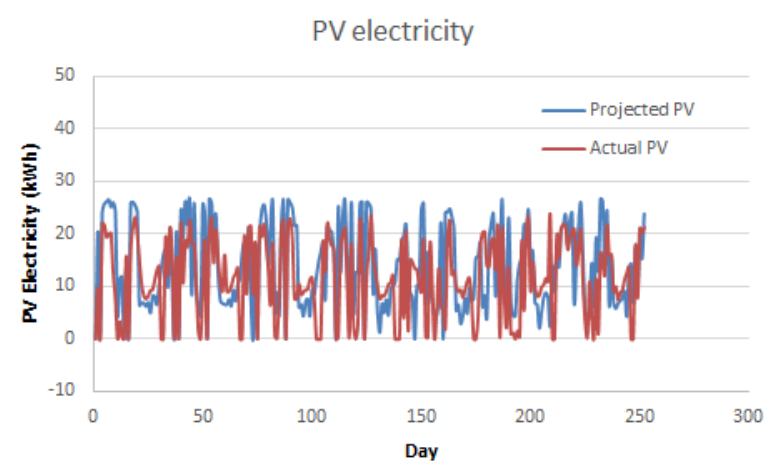

Fig. 9 Solar PV electricity.

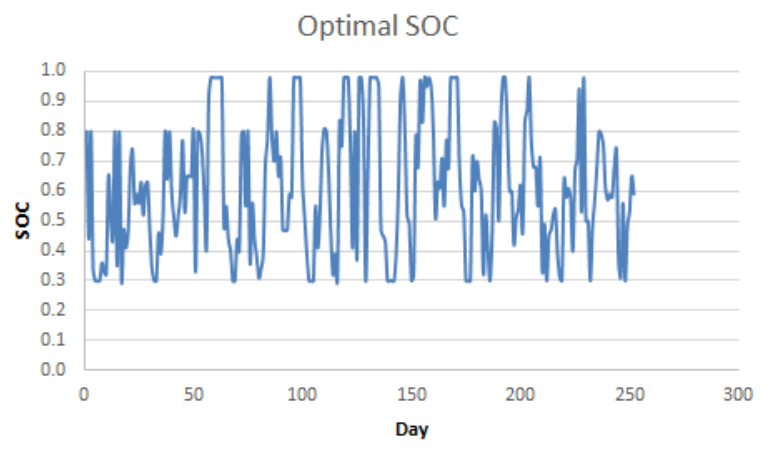

Fig. 10 Optimal target SOC.

\subsection{Battery Performance}

The performance of the battery storage is evaluated on a pack and cell level after one year of operation. The 220 cells are managed and balanced by six slave BMSs and a master BMS. These BMSs are powered by the battery only if the external power source is not available. The charged $\mathrm{Ah}$ and the discharge $\mathrm{Ah}$ are plotted in Fig. 11. The Ah difference is $230 \mathrm{Ah}$ between the Ah charged and the Ah discharged after the initial checkout of the battery system. After one year of operation, the difference of the Ah charged and the Ah discharged increased to $869 \mathrm{Ah}$. Hence the loss due to self-discharge is $639 \mathrm{Ah}$ over 8,086 h, which indicates that, the average self-discharging current of the battery pack is $79 \mathrm{~mA}$ and the self-discharge is 1.9 percent in a day.

The variation of the cell voltages as the battery is charged and discharged is shown in Fig. 12. The standard deviation of the cell voltage was calculated to assess the battery cell consistency during the resting, charging and discharging periods. Fig. 13 shows the

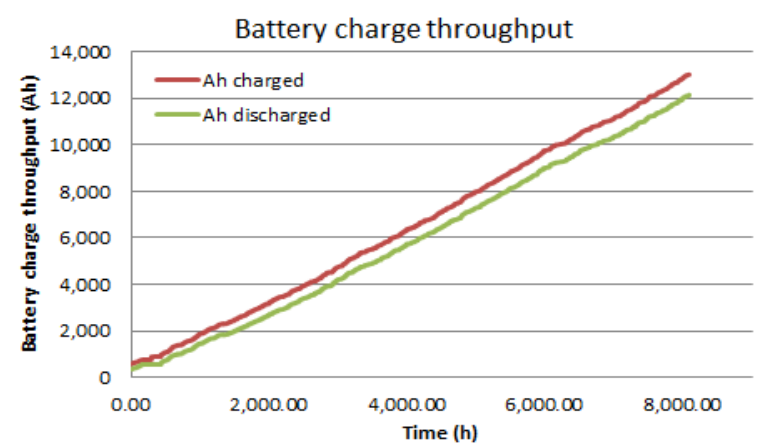

Fig. 11 Charged and discharged Ah over a year.

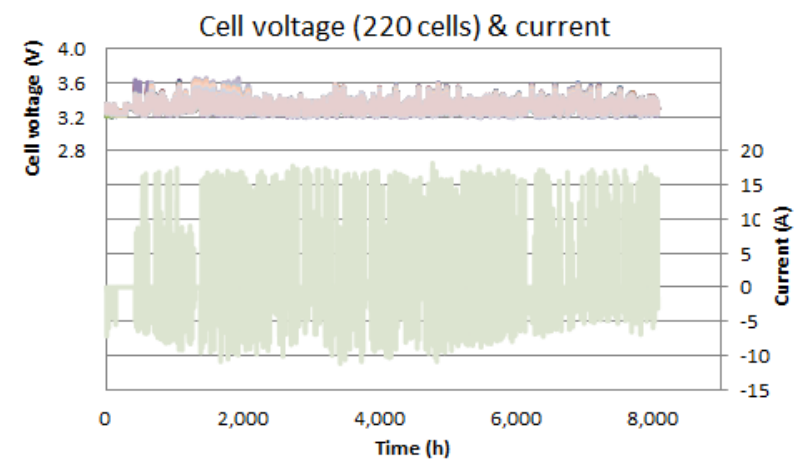

Fig. 12 Cell voltage and charging/discharging current. 


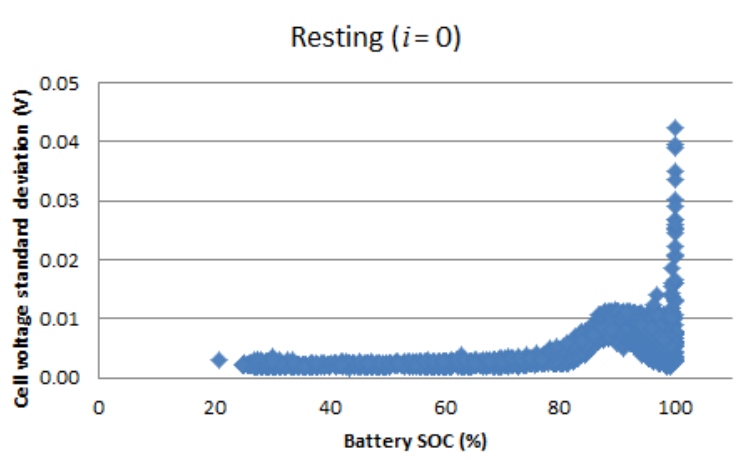

(a)

Charging $(i<0)$

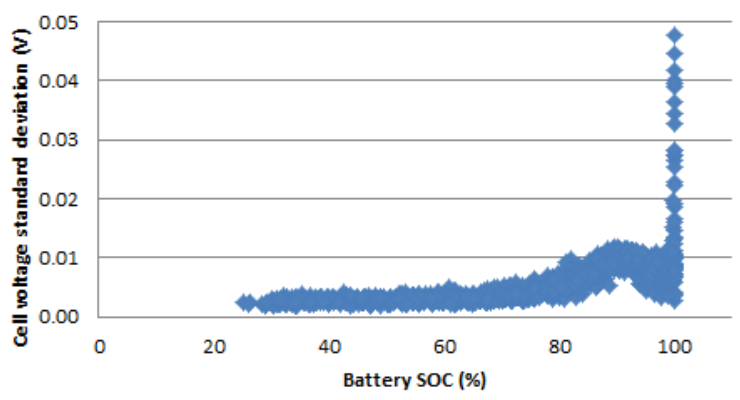

(b)

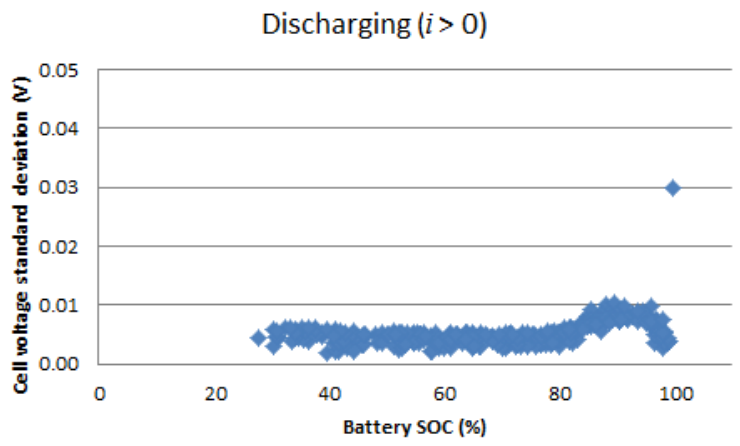

(c)

Fig. 13 Cell voltage standard deviation.

cell voltage deviation as a function of the battery SOC for a year. The analysis shows that, the $22050 \mathrm{Ah}$-cells show excellent voltage consistency with voltage deviation of less than $0.005 \mathrm{~V}$ for the battery SOC between $20 \%-80 \%$. The voltage deviation doubles when the battery SOC reaches $90 \%$. The comparison of cell voltage deviation at the beginning and after one year of operation (shown in Fig. 14) indicates that, the battery shows excellent cell voltage consistency and there is no obvious consistency deterioration during the battery resting, charging and discharging periods.

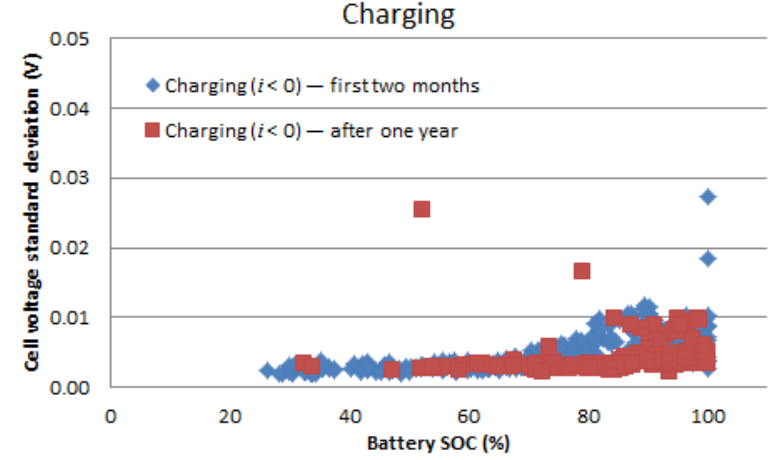

(a)

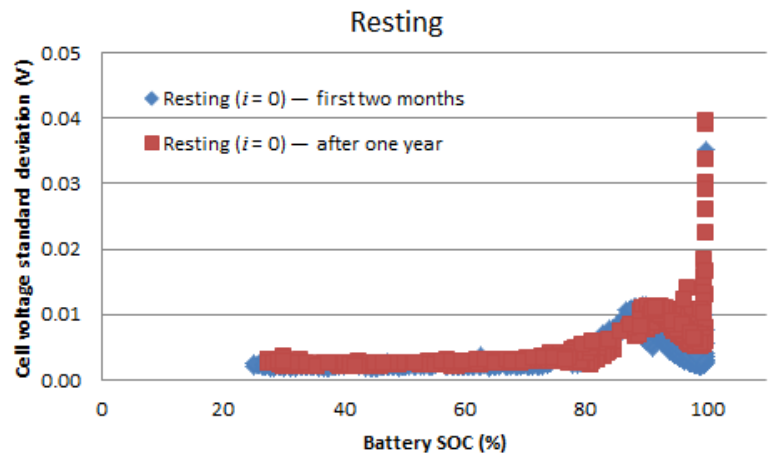

(b)

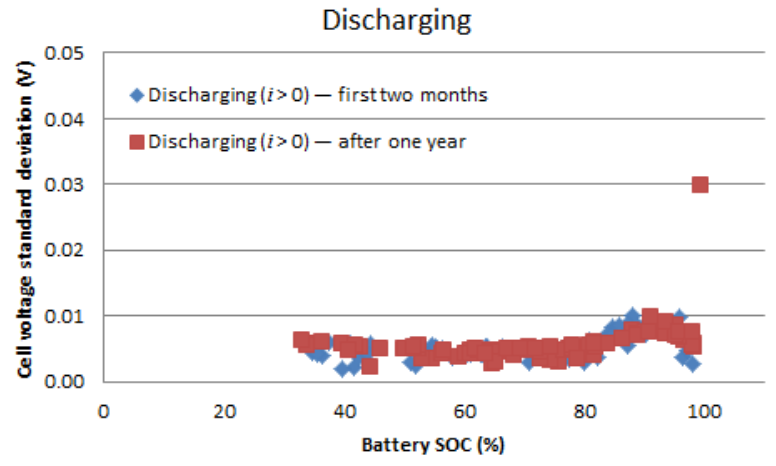

(c)

Fig. 14 Comparison of cell voltage deviation at the beginning and after one year of operation.

\section{Conclusions}

The PV-powered EV battery-buffered EV charging station with intelligent energy management has been demonstrated for more than a year on a workplace charging station at UC Davis West Village. The operation results show that, the system control, PV electricity estimation, EV charging load projection and battery SOC optimization are executed as expected. A $\mathrm{PV}$-integrated EV charging station equipped with a buffer battery and with intelligent energy management 
can almost eliminate the station's peak power demand and reduce the energy exchange with the utility grid by a factor of 2. The estimated PV electricity based on the extracted weather information reflects the actual PV electricity generation. More complicated PV electricity forecasting models with more accurate hour-by-hour weather information could improve the accuracy of the estimated PV electricity. The linear fit of the historical EV charging load data for each day of the week for the latest six-week period seems appropriate for extracting the charging pattern of a workplace EV charging station. Since the current charging station has only one outlet, the uncertainty and contingency will affect the result of the load demand projection. The intelligent energy management strategy is best suited for charging station systems having one large energy storage battery and multiple charging outlets. Data are being continuously collected from the system and examined on a regular basis as part of ongoing research.

\section{Acknowledgments}

We would like to give our special thanks to the California EISG (Energy Innovations Small Grant) program for their support to this research.

\section{References}

[1] Kondracki, R. 2014. "Solar Powered Charging Station."
Presented at the ASEE 2014 Zone I Conference, Bridgpeort, CT, USA.

[2] Sheng, S. 2013. "Energy Management for Solar Battery Charging Station." Presented at the 2013 IEEE 14th Workshop on Control and Modeling for Power Electronics (COMPEL), Salt Lake City, UT USA. doi:10.1109/COMPEL.2013.6626426.

[3] Goli, P., and Shireen, W. 2015. Control and Management of PV Integrated Charging Facilities for PEVs. Singapore: Springer Science + Business Media Singapore. Accessed February 06, 2016. http://www.springer.com.

[4] Almeida, R. H., and Brito, M. C. 2015. "A Review of Technical Options for Solar Charging Stations in Asia and Africa." Energy 3 (3): 428-49.

[5] Zhao, H., and Burke, A. F. 2014. "An Intelligent Solar Powered Battery Buffered EV Charging Station with Solar Electricity Forecasting and EV Charging Load Projection Functions.” Presented at the 2014 IEEE International Electric Vehicle Conference (IEVC), Florence, Italy.

[6] Sbordone, D., Bertini, I., and Di Pietra, B. 2015. "EV Fast Charging Stations and Energy Storage Technologies: A Real Implementation in the Smart Micro Grid Paradigm." Electronic Power Systems Research 120 (March): 96-108.

[7] Hoimoja, H., Rufer, A., and Dziechciaruk, G. 2012. "An Ultrafast EV Charging Station Demonstrator.” Presented at the SPEEDAM (International Symposium on Power Electronics, Electrical Drives, Automation and Motion) 2012, Sorrento, Italy.

[8] Sanzhong, B., Du, Y., and Lukic, S. 2010. "Optimum Design of an EV/PHEV Charging Station with DC Bus and Storage System." Presented at the ECCE (Energy Conversion Congress and Exposition) 2010, Atlanta, USA. 